\title{
A aplicação de processos químicos no tratamento de poluentes gerados pela extração e refino do petróleo
}

Carla Mabel Medeiros e Albuquerque e Silva* (Graduanda em Engenharia Civil na Universidade Federal Rural do Semi-Árido - UFERSA).

Cibele Gouveia Costa Chianca; (Ma. Professora Engenheira Civil na Universidade Federal Rural do Semi-Árido - UFERSA)

Israel Martins de Andrade; (Graduado em Enfermagem na Faculdade Unida da Paraíba - UNI PB)

*carla_mabel12@hotmail.com

\begin{abstract}
Resumo:
Considerado um combustível fóssil, o petróleo tem grande valor comercial, mas sua exploração também pode trazer riscos à saúde humana e do meio ambiente. O refino é a parte do processo que transforma o petróleo cru em matéria prima comercializável e a partir dele são produzidos diesel, gasolina, lubrificantes e outras substâncias. Caso essas etapas não sejam realizadas de forma correta elas podem ocasionar desastres ecológicos, poluição ambiental, desmatamento, impactos sobre ecossistemas marinhos e terrestres, poluição do ar, dentre outros. Em meio à situação, existem processos químicos que auxiliam na redução e tratamento dos poluentes oriundos da exploração e refino do petróleo. Essas técnicas podem fazer com que a indústria petrolífera continue a fornecer insumos necessários ao ser humano sem degradar o ambiente demasiadamente. Este trabalho tem como objetivo fazer uma análise teórica acerca dos impactos ambientais causados pela perfuração e refinamento do petróleo e apresentar soluções teoricamente viáveis usando tratamentos químicos. Foi realizado à base de pesquisa de revisão bibliográfica e foram utilizados materiais como livros, artigos, pesquisa documental de material publicado na internet pelos próprios órgãos relacionados à economia do petróleo. Os resultados apontam os principais efeitos ambientais negativos e as possíveis formas de prevenir e tratar tais impactos através de processos químicos. E dessa forma os estudos mostram que se adotados os processos químicos para a diminuição de emissão de poluentes atmosféricos, rejeitos sólidos e líquidos o petróleo pode se tornar mais ambientalmente viável em sua exploração.
\end{abstract}

\section{Palavras-chave:}

Combustível; Exploração; Fóssil; Poluição 


\section{INTRODUÇÃO}

O petróleo é um combustível fóssil produzido durante centenas de milhões de anos na história geológica da terra. Em sua composição estão presentes matéria orgânica decomposta, restos de vegetais, algas, alguns tipos de plâncton e restos de animais marinhos. A composição exata varia, dependendo do reservatório origem. É extraído da natureza na forma bruta, isto é, sem processamento algum. (Santos, 2012)

Apesar de tratar-se de um recurso natural essencial à sociedade, na sua forma bruta o petróleo é um produto bastante poluidor e isso ocasiona ao meio ambiente inúmeros problemas relacionados à fauna, flora e a própria população, por apresentar concentrações de enxofre, nitrogênio, oxigênio e metais. (Santos, 2012)

Para chegar aos consumidores, o petróleo bruto passa por uma série de etapas de processamento, o chamado refino, tendo em vista que no seu estado inicial possui pouquíssimas aplicações. (Santos, 2012)

A produção de petróleo no Brasil teve aumento acentuado nos últimos anos. Há cerca de 20 anos o petróleo brasileiro era, em sua maioria, oriundo de importações. Atualmente, o país já detém a auto-suficiência do produto. (PENA, 2015)

A Petrobrás, nos dias atuais, possui distribuído no território brasileiro 13 refinarias. O parque de refino produz mais de dois milhões de barris de derivados por dia, como diesel, gasolina, nafta, querosene de aviação, gás liquefeito de petróleo, lubrificantes, entre outras substâncias que servem de matéria prima para diversos outros produtos. (BRASIL, 2015)

O CONAMA define impacto ambiental como sendo qualquer alteração das propriedades físicas, químicas e biológicas do meio ambiente, causada por qualquer forma de matéria ou energia resultante das atividades humanas, que direta ou indiretamente, afetam a saúde, segurança e o bem estar da população; as atividades sociais e econômicas; a biota; as condições estéticas e sanitárias do meio ambiente; e a qualidade dos recursos ambientais. (CONAMA, 1986)

As atividades da indústria petrolífera e sua exploração em demasia é grande geradora de impactos ambientais, desde a extração até o consumo.

Os impactos ambientais decorrentes da atividade petrolífera são originados de etapas que vão desde a perfuração até o refinamento do petróleo, podendo ocasionar desastre ecológico, poluição ambiental, desmatamento, impacto sobre ecossistemas marinhos e terrestres, poluição de praias, de costões rochosos, do ar, estresse ambiental, dentre outros.

Ainda em seu refino podem ocorrer liberação de elevadas quantidades de despejos líquidos nos rios e solos, diversos gases nocivos na atmosfera e produzem resíduos sólidos de difícil tratamento e disposição, além de consumirem grande quantidade de água e energia.

Porém, atualmente existem técnicas que utilizam processos químicos que auxiliam no tratamento e prevenção dos poluentes oriundos da atividade petrolífera.

A partir das considerações citadas, este estudo possui como objetivo, fazer uma análise teórica acerca dos impactos ambientais da perfuração e refinamento do petróleo assim como apresentar soluções teoricamente viáveis usando tratamentos químicos.

\section{METODOLOGIA}

O desenvolvimento do trabalho baseou-se em pesquisa bibliográfica, recorrendo-se ao uso de materiais como livros, artigos e material publicado pelos próprios órgãos relacionados à economia do petróleo, como a Agência Nacional do Petróleo - ANP e a Petrobrás.

\section{RESULTADOS E DISCUSSÃO}

Nos resultados e discussão será feita uma análise e descrição dos principais impactos causados ao ambiente, devido as operações petrolíferas de explotação e refino. Com base nos argumentos de alguns autores serão apresentados os principais efeitos ambientais negativos e as possíveis formas de prevenir e tratar tais impactos através de processos químicos. 


\subsubsection{Explotação}

De acordo com Santos (2013), a palavra explotação denota à fase de produção, que é o processo de perfuração do solo para a extração do petróleo. Esse processo gera uma série de impactos ao meio ambiente como, por exemplo, o vazamento de óleo e os de ordem social que podem provocar mudanças nos hábitos das pessoas e animais que vivem nas regiões afetadas.

\subsubsection{Refino}

Santos (2013) diz que as refinarias é um dos maiores poluidores da indústria de petróleo, pois tem a capacidade de poluir a água, o solo e o ar.

A prática de refino de petróleo faz com que esse produto tenha mais valor comercial, pois, a partir desta etapa são produzidos diversos materiais que hoje são utilizados pela sociedade. Mas esse processo pode trazer prejuízos à população caso seus rejeitos não sejam tratados de forma adequada, dentre eles destacam-se contaminação hídrica, emissões de partículas para atmosfera, liberação casual de solventes e materiais ácidos ou alcalinos perigosos e a contaminação do solo e/ou da água (MARIANO, 2001).

\subsubsection{Poluentes atmosféricos}

Os poluentes atmosféricos são resultados de gases lançados na atmosfera pela atividade de refino e queima de petróleo.

Mariano (2005) menciona que os principais poluentes atmosféricos emitidos pelas refinarias são os óxidos de enxofre e nitrogênio, o monóxido de carbono, os materiais particulados, e os hidrocarbonetos (que geralmente constituem as emissões fugitivas de compostos orgânicos voláteis, os VOC’s). Esses poluentes são liberados nas áreas de armazenamento (tancagem), nas unidades de processo, nos eventuais vazamentos e nas unidades de queima de combustíveis fósseis (fornos e caldeiras) que geram calor e energia para consumo da própria refinaria.

Baseado no estudo de Mariano (2005), abaixo serão descritos os principais impactos ambientais e os métodos de tratamentos que envolvem processos químicos.

\subsubsection{I mpactos ambientais dos poluentes atmosféricos}

Muitos são os impactos causados pela poluição atmosférica provenientes do processo de refino no petróleo, entre eles, pode-se citar: chuvas ácidas, modificações das características dos solos devidas à lavagem dos mesmos pelas chuvas ácidas, mudanças do corpo aquático pelo aumento das concentrações de metais tóxicos e mudanças climáticas, devido ao aumento das concentrações de dióxido de carbono e de outros contaminantes na atmosfera. Causam também impactos sobre os materiais, pois os poluentes atmosféricos gasosos e particulados são conhecidos pelos efeitos sobre os metais (corrosão), pedras-mármore, pinturas, tecidos, borracha, couro e papel.

\subsubsection{Métodos de tratamento dos poluentes atmosféricos}

Para amenizar os efeitos negativos causados pelo refino de petróleo, destacam-se algumas técnicas que servem para controlar emissões de poluentes gasosos e outras que controlam emissões de material particulado. No controle de emissões de poluentes gasosos, são utilizadas técnicas como:

$\checkmark$ Controle por absorção de gases, que é uma técnica de separação de gases, onde se utiliza uma fase líquida como absorvente. É baseada na solubilidade preferencial ou na reatividade química do gás poluente com a fase líquida.

$\checkmark$ Controle por adsorção de gases, que é a reação dos gases poluentes com uma substancia adsorvente sólida.

$\checkmark$ A combustão também faz parte dessas técnicas, pois muitos compostos orgânicos liberados durante as operações de refino podem ser convertidos em $\mathrm{CO}_{2}$ e água, a partir do processo de combustão.

As técnicas de controlar emissões de material particulado são realizadas através de ciclones, filtros, coletores úmidos e precipitadores eletrostáticos. 


\subsubsection{Efluentes hídricos}

Mariano (2005) define os efluentes de processo como qualquer água ou vapor condensado que tenha contato com o óleo, na sua forma líquida ou gasosa, e que pode, portanto, conter óleo ou outros contaminantes químicos. Incluem soluções ácidas, soda exausta, águas de lavagem do petróleo cru e dos derivados, a água proveniente da etapa de dessalinização, os condensados resultantes da retificação a vapor e da destilação, assim como da limpeza ou regeneração com vapor dos catalisadores de processo.

Santo (2010) reforça a idéia, mensurando que os efluentes das refinarias de petróleo incluem óleos livres e emulsionados provenientes de rupturas, derrames, descargas de reservatórios e de outras origens.

Geralmente os efluentes líquidos ao ser descartados não recebem o devido tratamento, o que ocasiona diversos efeitos negativos sobre o meio ambiente. Estas consequências podem ser de caráter sanitário, ecológico, social ou econômico.

\subsubsection{I mpactos ambientais dos efluentes hídricos}

$\checkmark$ Prejuízos ao uso de água por indústrias, irrigação, pesca e recreação, devido a existência de substâncias tóxicas, o que agrava os problemas de escassez de água de boa qualidade;

$\checkmark$ A liberação de alguns metais pesados nos efluentes, como chumbo, ferro, cádmio e cobre, podem ocasionar intoxicação dos organismos aquáticos e modificações severas na fauna e flora aquáticas;

$\checkmark$ A ocorrência de pH’s muito ácidos ou alcalinos nos efluentes, pode causar corrosão, efeitos negativos sobre a fauna e a flora e prejuízos à utilização desta água na irrigação;

$\checkmark$ A liberação do amoníaco nos efluentes, a partir de compostos nitrogenados presentes no petróleo, promove a eutrofização dos corpos aquáticos, o que causa prejuízo na utilização daquela água.

$\checkmark$ A elevação da temperatura da água, causadas pelo despejo de águas usadas no resfriamento, possui como consequência o aumento das reações químicas e biológicas podendo acarretar a elevação da toxidez de alguns elementos e compostos químicos, redução da quantidade de oxigênio dissolvido e diminuição da viscosidade da água, o que pode ocasionar a redução das espécies.

$\checkmark$ A presença elevada de sais nos efluentes causam a eliminação de algumas espécies de animais aquáticos.

\subsubsection{Métodos de tratamento dos efluentes hídricos}

Existem diversos tipos de tratamento, entre eles os que contam com os processos de neutralização, coagulação química seguida por sedimentação, e os processos de filtração e flotação.

A floculação química seguida de sedimentação consiste na adição de um reagente químico ao efluente de forma a promover a união das partículas e posterior precipitação da sujeira.

Podem ser também de natureza química, física ou biológica. Incluem o uso de lodos ativados, lagoas aeradas, filtros biológicos, lagoas de estabilização, torres de oxidação, filtração, adsorção em carvão ativo e osmose reversa.

É importante fazer a remoção dos cianetos contidos nos efluentes, pois estes além de ser venenosos, podem originar o gás cianídrico (HCN), que é altamente tóxico. Esse procedimento pode ser realizado através do tratamento com sulfato ferroso, que precipita o cianeto sob a forma de ferrocianeto, que pode ser então retirado da mistura por sedimentação (MARIANO, 2005).

\subsubsection{Resíduos sólidos}

Segundo Mariano (2005) os resíduos sólidos mais gerados na indústria de refinamento de petróleo incluem: a lama dos separadores de água e óleo (API), a lama dos flotadores a ar dissolvido e a ar induzido, os sedimentos do fundo dos tanques de armazenamento do petróleo cru e derivados, borras oleosas, as argilas de tratamento, lamas biológicas, lamas da limpeza dos trocadores de calor e das torres de refrigeração, além de sólidos emulsionados em óleo. Esses resíduos são constituídos de elementos químicos tóxicos que geram impactos negativos ao meio ambiente e ao ser humano de alguma maneira. 


\subsubsection{I mpactos ambientais dos resíduos sólidos}

Devido ao lançamento de resíduos sólidos originados pelas refinarias, o meio ambiente sofre diariamente efeitos negativos. Dentre os impactos gerados pela disposição de resíduos sólidos pode-se citar:

$\checkmark$ Poluição da água, pelo carreamento superficial ou pela infiltração dos detritos para os corpos hídricos;

$\checkmark$ Liberação de gases tóxicos;

$\checkmark$ Alterações químicas do solo provocadas pelo descarte de resíduos e ainda impactos sobre os organismos vivos que habitam o solo.

\subsubsection{Métodos de tratamento dos resíduos sólidos}

O tratamento de resíduos sólidos busca minimizar ou eliminar os constituintes perigosos do resíduo.

Algumas das formas de serem operacionalizados são através da destruição química dos produtos indesejáveis e da alteração da estrutura química de determinados produtos, tornando mais fácil a sua assimilação por parte do meio ambiente.

Os métodos de tratamento de resíduos sólidos usados nas refinarias, são em muitas vezes métodos químicos, que se baseiam nas diferenças das propriedades químicas dos diversos componentes dos resíduos e envolvem uma ou mais reações químicas, como: neutralização, precipitação, fotólise e reações de oxi-redução.

\section{CONCLUSÕES}

A partir da revisão bibliográfica feita foi possível concluir que a atividade petrolífera é geradora de insumos e recursos que produzem materiais necessários ao homem nos dias atuais. Outros benefícios criados a partir da exploração do petróleo é o desenvolvimento econômico que é propiciado nas regiões produtoras. Os municípios dos estados produtores de petróleo recebem royalties que são recursos financeiros destinados a compensar possíveis degradações ambientais e podem ser investidos em áreas fundamentais para a sociedade, como educação, saúde e segurança pública (MENDES e KOHLER, 2011).

Nesta atividade uma etapa é indispensável, o refino. É no refino que o petróleo é transformado em insumo comerciável. Porém esta atividade pode trazer prejuízos á saúde do homem e do ambiente. No homem podem ocorrer problemas respiratórios, cardiovasculares e na visão, além de causar alteração da biota, na paisagem e no ar das regiões exploradas.

Nos dias atuais existem diversas técnicas com processos químicos que ajudam a diminuir os impactos causados pela explotação e refino do petróleo, como controle por absorção de gases, controle por adsorção de gases e combustão. Para os resíduos sólidos podem ser realizadas a destruição química dos produtos indesejáveis, além da separação da massa de resíduos e alteração da estrutura química de determinados produtos. Para os efluentes hídricos existem técnicas como a coagulação química.

Essas manobras podem diminuir os efeitos agressivos da exploração e refino do petróleo, causando menos riscos à população e ao meio ambiente.

Portanto conclui-se que a exploração do petróleo traz benefícios à sociedade, produz matérias primas necessárias ao consumo humano e fortalece a economia de países, estados e municípios produtores, mas é preciso salientar sobre os riscos da extração desacerbada, dos riscos que o refino pode causar com impactos na saúde da população e no ambiente, devido à emissão de agentes químicos.

Dessa forma adotando esses processos químicos para a diminuição de emissão de poluentes atmosféricos assim como dos rejeitos sólidos e líquidos, essa fonte de energia não renovável tornar-seia mais ambientalmente viável a traria menos prejuízos à população próxima às áreas de exploração. 
The application of chemical processes in the treatment of pollutants generated by the petroleum extraction and refining

\begin{abstract}
Considered a fossil fuel, oil has great commercial value, but his holding may also pose risks to human health and the environment. The refining is part of the process that turns crude oil into marketable raw material and from it are produced diesel, gasoline, lubricants and other substances. If these steps are not carried out properly they can cause ecological disasters, environmental pollution, deforestation, impacts on marine and terrestrial ecosystems, air pollution, among others. Amid the situation, there are chemical processes that assist in the reduction and treatment of pollutants resulting from the exploration and refining of petroleum. These techniques can cause the oil industry continue to provide necessary inputs to humans without degrading the environment too. This paper aims to make a theoretical analysis about the environmental impacts caused by drilling and refining of oil and theoretically present viable solutions using chemical treatments. Literature review was conducted to research base and used materials such as books, articles, documentary research material published on the Internet by the organs related to the oil economy. The results indicate any significant adverse environmental effects and possible ways to prevent and treat these impacts through chemical processes. And so studies show that adopted the chemical processes to reduce the emission of air pollutants, solid waste and liquid oil can become more environmentally viable in their exploitation.
\end{abstract}

Keywords: Fuel; Exploration; Fossil; Pollution 


\section{Referências bibliográficas}

BRASI L. Refino. 2015. Disponível em: <http://www.petrobras.com.br/pt/nossas-atividades/areas-deatuacao/refino/>. Acesso em : 03 de março de 2015.

CONAMA (Brasil) (Org.). RESOLUÇÃO CONAMA № 001, de 23 de janeiro de 1986. Disponível em: < http://www.mma.gov.br/port/conama/res/res86/res0186.html >. Acesso em: 12 de março de 2015.

MARIANO, J.B. I mpactos Ambientais do Refino de Petróleo. Interciência, 2005.

MARIANO, J.B. I mpactos Ambientais do Refino de Petróleo. Dissertação, Ciências de Planejamento Energético, Universidade Federal do Rio de Janeiro. 2001.

MENDES, M e KOHLER, M. Os estados e municípios devem receber royalties do petróleo? Em Brasil, Economia e Governo. 2011. Disponível em> <HTTP:// http://www.brasil-economiagoverno.org.br/2011/06/06/os-estados-e-municipios-devem-receber-royalties-de-petroleo/>. Acesso em: 12 de outubro de 2015.

PENA, R. F. A. Produção de Petróleo no Brasil. Em Geografia humana do Brasil. 2015. Disponível em: <http://www.mundoeducacao.com/geografia/producao-petroleo-no-brasil.htm>. Acesso em: 29 de setembro de 2015.

SANTO, C.M.E. A Indústria de Refinação de Petróleo: Características e Tratamento das Águas Residuais. Engineering and Technology J ournal, v. 1, p. 21 - 46, 2010.

SANTOS, P.V. I mpactos Ambientais Causados pela Perfuração de Petróleo. Cadernos de Graduação - Ciências Exatas e Tecnológicas, v. 1, p. 153 - 163, 2012.

SANTOS, N.F. Estudo dos impactos ambientais causados pela exploração, explotação e refino do petróleo. 2013. Trabalho de Conclusão de Curso, Universidade Federal Rural do SemiÁrido. Angicos - RN. 